\title{
Attachment patterns during Year 12: Psychologi- cal symptoms, rejection sensitivity, loneliness, social competence, and support as correlates of stability and change
}

\begin{abstract}
Year 12 students are in a transitional year, academically and interpersonally. This year involves many changes and the need for students to make future plans, which can be a challenge for many adolescents. During times of transition, such as Year I2, expectations and beliefs about relationships and the relational self (i.e., attachment patterns) may undergo changes. Identifying attachment patterns among Australian Year 12 students was the first aim of this 6-month longitudinal study $(N=130, M$ age $=16.4$ ). A second aim of this study was to determine correlates of attachment change and stability. These correlates included psychological symptoms, loneliness, rejection sensitivity, social competence, and social support. Using an adolescent version of Bartholomew and Horowitz's (1991) Relationship Questionnaire, self-reported attachment style showed some change, with $36 \%$ of adolescents changing attachment style category during the study. Adolescents were classified into groups based on their attachment styles at the two assessments. Groups included adolescents who were stably secure, stably insecure, changed to secure and changed to insecure. When groups were compared, most hypothesised differences were found. First, stably secure individuals had the most positive psychological functioning, and they had the most stable and positive perceptions of self and others when compared to other groups. Second, stably insecure adolescents were less well-adjusted than others. Third, the changed to secure group showed improvements in functioning over time. However, it was not clear that adjustment had declined in the changed to insecure group.
\end{abstract}

Keywords: Attachment, Social competence, Rejection, Social support, Longitudinal

In classic attachment theory, Bowlby (1973) suggested that childhood experiences of relationships lead to the formation of expectations and beliefs about the self, others, and the broader social world. These expectations are expected to generalise and shape subsequent beliefs about the self in relationships and social interactions across the life span. In most conceptions of attachment, these beliefs, referred to as internal working models, are described as relatively stable, "from the cradle to the grave" (Bowlby, 1977, p.129, Collins \& Allard, 2001). At 
the same time, Bowlby emphasised that for internal working models to remain functional, they must be flexible and open to change in response to new insights and relational experiences (Feeney \& Noller, 1996), and there is evidence that attachment patterns may change over time (e.g., Waters, Weinfield, \& Hamilton, 2000). Hence, an understanding of stability and change in attachment patterns can be central to an understanding of interpersonal and social functioning.

Attachment has often been assessed with categorical measures; individuals usually are assigned to one of three or four discrete attachment styles (Bartholomew \& Horowitz, 1991; Hazan \& Shaver, 1987). These categories can broadly be conceptualised as "secure" or "insecure" attachment patterns. Stability and change in these categorical attachment patterns have been investigated in childhood (e.g., Egeland \& Farber, 1984), from childhood into early adulthood (e.g., Lewis, Feiring, \& Rosenthal, 2000) and during adulthood (e.g., Baldwin \& Fehr, 1995; Cozzarelli, Karafa, Collins, \& Tagler, 2003; Davila, Burge, \& Hammen, 1997). Summarising across these studies, roughly $30 \%$ of individuals show a change in attachment style over time, as assessed by selfreport or interview methods over varying lengths of time, ranging from 1 week (Pistole, 1989) to 4 years (Kirkpatrick \& Hazan, 1994). Yet, there is negligible longitudinal research addressing the stability of attachment pattern during the high school years. To fill this gap, the first objective of the current study was to investigate attachment style over a 6-month period among students in their final year of high school (Year 12, about age 17).

Year 12 students are in a transitional year, both academically and interpersonally. This year involves many changes and students need to make plans for their futures. Investigations of attachment and attachment change during stressful, transitional periods have been recommended by researchers. This recommendation has been made because attachment-related needs are expected to be most salient during stressful times when individuals (a) encounter new social information, thereby increasing the likelihood of exposure to information inconsistent with existing working models; and (b) are more likely to reflect upon and re-evaluate existing models (Scharfe \& Bartholomew, 1994; Simpson, Rholes, Campbell, \& Wilson, 2003). Year 12 students have many experiences that expose them to new social information, such as visiting potential sites for further study and beginning to take on vocational training or jobs. During year 12 , students also have a growing awareness that the nature of their contact with their peer group, and perhaps their family, will be changing dramatically. Given these changes and expectations of change, and the potential stress that can come with change, we expected that year 12 would be a time when attachment-related needs would ascend in importance and new experiences and the knowledge of impending major life changes might prompt changes in attachment patterns. In support of our expectations, Bowlby (1977) viewed adolescence as a formative period in the establishment of attachment patterns and wrote that "during adolescence early attachments may attenuate and become supplemented by new ones" (p. 203). All of these considerations resulted in our expectation that year 12 is one important time of life to study attachment change. 


\section{Correlates of Stability and Change in Attachment Style}

Knowing if adolescents have experienced change in attachment style is only part of the story. It is also important to know what might antecede or correlate with stability and change. The second objective of the current study was to identify factors associated with stability and change in adolescents' attachment style. Based on attachment theory and empirical evidence, specific factors were predicted to correlate with attachment patterns over time. These factors included psychological symptoms, loneliness, rejection sensitivity, social competence, and perceived social support from friends and family. Correlates of attachment style change have not been extensively examined within any developmental period, but there are notably fewer studies of high school students (Cozzarelli et al., 2003).

\section{Psychological symptoms and loneliness}

Studies of university students and adults suggest that psychological symptoms are associated with changes in attachment style, with longitudinal study findings indicating that there are decreasing symptoms when a secure attachment pattern emerges and increasing symptoms when an insecure attachment pattern emerges (Cozzarelli et al., 2003; Davila et al., 1997; Lopez \& Gormley, 2002). Relatedly, in cross-sectional studies, loneliness has been elevated in individuals who are classified as insecure as compared to secure, and this has been found among adults (Hazan \& Shaver, 1987), university students (Kobak \& Sceery, 1988) and high school students (Larose \& Boivin, 1997). To our knowledge, there has been no previous longitudinal study of loneliness as a correlate of attachment style change over time.

\section{Rejection sensitivity, social competence, and social support}

In attachment theory, individuals with different attachment styles have been described as differing in their generalised beliefs and expectations about the self, others and the social world. For example, people vary in their anxiety about possible rejection by others and their expectation that they will be rejected (Downey \& Feldman, 1996). Feldman and Downey (1994) have labelled this "rejection sensitivity." Theory suggests that sensitivity to rejection is one developmental outcome of negative experiences, such as social rejection, in important relationships (Feldman \& Downey). The experience of social rejection also has been found to be detrimental to well-being and interpersonal functioning. Among late adolescents, rejection sensitivity has been linked with an insecure attachment pattern, when attachment was assessed by Hazan and Shaver's (1987) self-report measure (Feldman \& Downey). Given this theory and evidence, we expected that change in attachment style should be associated with change in rejection sensitivity over time.

It has been argued that a change in attachment style also should be associated with other changes in an individual's underlying expectations of others and the self, particularly those that impact social behaviours, such as perceptions of social competence (Cozzarelli et al., 2003). Individuals classified as secure are 
expected to carry forward expectations that social partners will be available and responsive to them, whereas individuals classified as insecure may not expect support from others. In studies of late adolescents and adults, crosssectional evidence has supported the theoretical expectation that perceptions of social competence are associated with attachment style (Anders \& Tucker, 2000; Collins \& Read, 1990; Kobak \& Sceery, 1988). To our knowledge, only one previous longitudinal study has studied attachment style change and patterns of social competence over time. In this study, social competence increased over time among 207 young, university students (age $M=18, S D=.44$ ) who changed from an insecure attachment style to a secure attachment style over a 5-month period of time (Lopez \& Gormley, 2002).

Cross-sectional evidence, but no longitudinal study, also has linked attachment style with perceptions of social support (Collins \& Feeney, 2004; Kobak \& Sceery, 1988). For example, using a self-report continuous measure of attachment, Anders and Tucker (2000) found that 104 late adolescents who were relatively more anxiously and avoidantly attached had relatively smaller social support networks and lower levels of satisfaction with their social support. Similar results emerged in two separate investigations of the associations between perceptions of support and categorical attachment style (Davis, Morris, \& Kraus, 1998; Ognibene \& Collins, 1998), and in the one longitudinal study, of adult women (Cozzarelli et al., 2003). In the current study, we expected that changes in perceptions of social competence and perceived social support from friends and family would be associated with attachment style change, with increases in competence and support expected when attachment patterns changed from insecure to secure, and decreases expected when the opposite attachment pattern over time was found.

\section{Measurement of Attachment in Adolescence}

With the continued application of attachment theory to adolescents and adults, there are now more than 20 measures of attachment (Shaver \& Clark, 1994). Approaches to investigating adolescent and adult attachment differ with regards to: (a) the relationship domain of focus (parent, peer, or romantic relationships); (b) the methodology used for classifying individuals (self-report, interview, or Q-sort); and (c) the way attachment is conceptualised, such as continuous dimensions (Collins \& Read, 1990), categories (Hazan \& Shaver, 1987) or prototypes (Bartholomew \& Horowitz, 1991).

Of most importance to the current study, Bartholomew and Horowitz (1991) argued that to be theoretically specific, attachment style should reflect two types of internal working models that centre on positive and negative models of self (as worthy vs. unworthy of love), and others (as trustworthy and available vs. unreliable and rejecting). These two dimensions (model of self and model of others) combine to create four attachment styles - secure, preoccupied, fearful, and dismissing. Individuals classified as secure are characterised by a general comfort with closeness, have positive self-images and optimistic expectations of others. For example, compared with individuals classified as insecure, 
secure individuals have fewer self-doubts, are better liked by others, are less concerned about rejection, and view others as more trustworthy, altruistic and dependable (Hazan \& Shaver, 1987). The remaining three styles - preoccupied, fearful, or dismissing - are variants of an insecure attachment style classification. Individuals classified as preoccupied (negative self/positive other) reflect a sense of feeling unloved, but view others as generally trustworthy and available, thus often worry about being rejected. Individuals classified as fearful (negative self/negative other) similarly have a sense of unworthiness and not worthy of love, combined with the expectation that others will be untrusting and rejecting. Individuals classified as dismissing (positive self/negative other) do possess a sense of worthiness and a positive self-image, but have a negative disposition toward others, considering attachment figures as unreliable and uncaring. In one study, the approximate size of each attachment style category was $60 \%$ secure, 15\% dismissing, 10\% preoccupied and 15\% fearful (Bartholomew \& Horowitz). Similar findings have been found in more recent studies (e.g., Bartholomew, 1994; Brennan \& Morris, 1997; Searle \& Meara, 1999). A four-category measure was used here in which adolescents selected their attachment category from a list of four descriptors. We then focused on dichotomous attachment classification of secure (one of the four descriptors) or insecure (the other three descriptors) to be consistent with previous research on categorical change in attachment style (e.g., Cozzarelli et al., 2003; Davila et al., 1997).

\section{Current Study Objectives and Hypotheses}

In summary, there were two objectives of this 6-month longitudinal study (two waves) of students in their last year of high school. The first objective was to determine the degree of stability and change in attachment style. The second objective was to delineate factors that were associated with attachment style change over time. Guided by studies of late adolescents and adults, we hypothesised that psychological symptoms, loneliness, rejection sensitivity, social competence, and perceived social support from friends and family would be associated with changes in attachment style. Given that attachment concerns have been described as undergoing significant transformation during adolescence and in times of environmental stress, this research was designed to inform attachment theory and complement previous studies of older students and adults.

\section{Method}

\section{Participants}

At Time 1 (T1), 164 Year 12 students (age $\mathrm{M}=16.4, \mathrm{SD}=0.6,48 \%$ males), with parental permission completed the questionnaire. At Time 2 (T2), approximately six months later, 130 students ( $80 \%$ of the $\mathrm{T} 1$ sample; $44 \%$ males) were reassessed. Two participants were not included in all analyses, because they had not completed the social support from family and friend scales, or the social competence and psychological symptoms scales. All students attended public high schools in an urban area in SE Queensland, Australia. 
The ethnic/racial composition of the study was majority white/Caucasian (88\%). Overall, $81 \%$ lived with their parent/s (mother, father, or both) and 10\% lived in blended families (father/mother and step-parent). About one-third of parents (33\% of mothers, 30\% of fathers) had left high school before completing year 12; $35 \%$ of mothers and $20 \%$ of fathers had completed Year 12; $26 \%$ of mothers and $29 \%$ of fathers had attended university. The remainder of parents left school before Year 10 or adolescents did not know their parents' education level.

T-tests were performed to determine whether those who participated at T2 differed from those lost to attrition. There were no significant age, gender and ethnicity differences, and there was no significant difference in attachment style. There also were no differences in psychological health $t(161)=-1.01, p=.31$, loneliness, $t(159)=1.19, p=.24$, rejection sensitivity, $t(39)=-0.93, p=.36$, social competence, $t(154)=-0.59, p=.55$, perceived social support from friends $t(157)=.-0.74, p=.46$, and social support from family $t(67)=-0.22, p=.83$.

\section{Procedure}

Following ethical clearances (e.g., Griffith University Human Research Ethics Committee, Queensland Education Department) and receipt of written consent from school principals, the project was described to year 12 students, and parental information/consent forms were distributed. The T1 questionnaire was administered in about the third month of the school year. The T2 questionnaire was administered approximately six months following T1. Data collection took place in classrooms under the supervision of researchers.

\section{Measures}

Demographic information

Respondents provided information about their gender, age, ethnic/racial background, dating status, and living arrangements. Information about parents' marital status, educational background and occupation was also gathered.

\section{Attachment style}

Attachment style was measured with an adolescent version of Bartholomew and Horowitz's (1991) Relationship Questionnaire (RQ). The adult version of this measure was modified by Scharfe (not dated) to be more appropriate for use with adolescents. The RQ consists of four paragraphs, each providing a prototypical description of one of the four attachment styles (secure, and three insecure categories of preoccupied, fearful, and dismissing). The order of the paragraphs was randomised across participants.

The RQ yields categorical (self-selected) and continuously scaled data. First, participants rated the extent each prototype described how they conceptualised others and relationships, using a scale from 0 (not at all like me) to 6 (very much like me). Next, they were asked to endorse the one prototype that described them best. An attachment style (secure, preoccupied, fearful, or dismissing) was assigned 
based on this selection. Collapsing the three insecure attachment styles formed a dichotomous secure-insecure attachment classification. Scharfe and Bartholomew (1994) examined stability of attachment categories when using this forced choice method. They found that $59 \%$ of individuals had stable attachment style over eight months. Stability of the continuous ratings of the four attachment styles over the 8-month interval was moderate with an average test-retest correlation of .51 (Scharfe \& Bartholomew, 1994). Additionally, the RQ has been correlated with other attachment measures, such as the Adult Attachment Interview ( $\mathrm{r}$ from .22 to .50; Griffin \& Bartholomew, 1994) and Hazan and Shaver's threegroup measure (Feeney \& Noller, 1996).

Guided by the research hypotheses, and to parallel previous research (e.g., Cozzarelli et al., 2003; Davila et al., 1997), we focused on identifying groups of adolescents who changed from insecure to secure (and vice versa) or remained stable. Consequently, change in dichotomous attachment categories of secure and insecure, based on the self-selected adolescent RQ category, was our focus rather than finer distinctions between individual attachment styles (e.g., change from fearful to dismissing) or change in adolescents' ratings of each attachment style. The continuous data was collected primarily to examine the concurrent validity of the self-selected attachment category. We found 12 mismatches when we compared an adolescent's endorsement of an attachment style to the category he/she rated most like himself/herself. Analyses were repeated excluding these 12 participants, and results are described.

\section{Psychological symptoms}

Psychological symptoms were assessed with 25 items from the Brief Symptom Inventory (BSI; Derogatis \& Melisaratos, 1983). These items comprised the subscales of depression (7 items), anxiety (6 items), hostility (5 items) and somatisation ( 7 items). Participants rated the extent to which they were bothered or distressed by each symptom during the past two weeks on a scale from 0 (not at all) to 4 (extremely). Example symptoms included "feelings of worthlessness" (depression), "feeling tense or keyed up" (anxiety), "temper outbursts" (hostility), and "pains in heart or chest" (somatisation). Subscale scores were formed by averaging relevant items, with higher scores indicating the presence of more psychological symptoms. A principle component factor analysis with $\mathrm{T} 1$ data revealed that the four subscales loaded on a single factor with factor loadings of $.90, .82, .80$, and .87 for anxiety, somatisation, hostility, and depression, respectively. Thus, a composite measure of psychological symptoms was created by averaging the four subscale scores, with higher scores indicating the presence of more psychological symptoms. This procedure follows that used by Cozzarelli et al. (2003). Cronbach's $\alpha$ for psychological symptoms was .93 (T1) and $.94(\mathrm{~T} 2)$.

\section{Loneliness}

Loneliness was assessed by the 20-item UCLA Loneliness Scale (Russell, Peplau, \& Cutrona, 1980). Items were rated on a 4-point scale ranging from 0 (never) to 
3 (often). Example items included "There is no one I can turn to" and "There are people who really understand me." After reversing positively worded items, all 20 items were averaged, with higher scores representative of greater loneliness. In the current study, the internal consistency was high. Cronbach's $\alpha=.93$ at T1 and .94 at $\mathrm{T} 2$.

\section{Rejection sensitivity}

Anxiety about and expectations of rejection were assessed by the University Student Rejection Sensitivity Questionnaire (Ayduk et al., 2000; Downey \& Feldman, 1996; Feldman \& Downey, 1994), but was slightly modified to ensure all items were applicable to high-school students (e.g., 'professor' was replaced with 'teacher') and one item was omitted ("You ask your boyfriend/girlfriend to move in with you"). The RSQ consisted of 17 hypothetical situations involving potential rejection (e.g., "Imagine that you ask someone you don't know well out on a date"). For each scenario, participants rated (1) degree of concern about the outcome (e.g., "How concerned or anxious would you be over whether or not the person would want to go out with you?") on a scale ranging from 1 (very unconcerned) to 6 (very concerned) ("rejection concern"), and (2) likelihood that the other person in the hypothetical situation would respond in an accepting manner (e.g., "I would expect that the person would want to go out on a date with me") ranging from 1 (very unlikely) to 6 (very likely) ("acceptance expectancy"). Rejection sensitivity was calculated by applying the following formula: Rejection sensitivity $=$ (rejection concern) $\mathrm{X}$ (7 - acceptance expectancy), and averaging the resulting 17 scores. Higher scores reflected greater rejection sensitivity. High internal reliability was found in the current study, Cronbach's $\alpha=.87$ at T1 and .90 at $\mathrm{T} 2$.

\section{Social competence}

Perceived social competence was assessed using the Texas Social Behaviour Inventory (Helmreich \& Stapp, 1974). Sixteen items were rated from 0 (not at all characteristic of me) to 4 (very much characteristic of me). A sample item is "I would describe myself as self-confident." After reversing necessary items, items were averaged. Inter-item correlations were high in the current study, $\alpha=.85$ and .84 at $\mathrm{T} 1$ and $\mathrm{T} 2$.

\section{Perceived social support}

Social support was measured with the Perceived Social Support Scale (Procidano \& Heller, 1983). The PSS assessed support from friends (PSS-Fr) and from family (PSS-Fa). Each subscale has 20 items. An example items is "I rely on my friends / family for emotional support." Participants answer 1 (yes), 0 (no), or don't know (not scored) for each statement. After reversing the necessary items, PSS-Fr and PSS-Fa scores were calculated by averaging the 20 items, with higher scores indicating a perception of greater social support. Internal reliabilities of both scales were high, PSS-Fr $\alpha=.83$ at T1 and .95 at T2, PSS-Fa $\alpha=.91$ at T1 and .95 at T2. 


\section{Results}

\section{Descriptive Information}

Descriptive statistics are shown in Table 1 and correlations between variables measured at T1 and T2 are presented in Table 2. Most variables were correlated with modest, but significant, positive correlations between measures of maladjustment (e.g., loneliness and rejection sensitivity) and negative correlations between measures of negative and positive functioning (e.g., loneliness and social support).

\begin{tabular}{|c|c|c|c|c|c|}
\hline \multirow[b]{2}{*}{ Construct $^{\mathrm{a}}$} & \multirow[b]{2}{*}{ Range } & \multicolumn{2}{|c|}{$\mathrm{T} 1$} & \multicolumn{2}{|c|}{$\mathrm{T} 2$} \\
\hline & & $M$ & $S D$ & $M$ & $S D$ \\
\hline Psychological symptoms & $0-4$ & 0.96 & 0.69 & 0.95 & 0.73 \\
\hline Loneliness & $0-3$ & 0.88 & 0.56 & 0.87 & 0.58 \\
\hline Rejection Sensitivity & $0-36$ & 9.33 & 3.74 & 8.91 & 3.94 \\
\hline Social competence & $0-4$ & 2.52 & 0.59 & 2.53 & 0.57 \\
\hline Social support from friends & $0-1$ & 0.77 & 0.24 & 0.78 & 0.25 \\
\hline Social support from family & $0-1$ & 0.71 & 0.30 & 0.75 & 0.30 \\
\hline
\end{tabular}

${ }^{a}$ On average, there was no significant change over time in any construct.

Table 2. Pearson's Correlations among Continuous Measured Variables

\begin{tabular}{|c|c|c|c|c|c|c|}
\hline Construct & 1 & 2 & 3 & 4 & 5 & 6 \\
\hline 1. Psychological symptoms & - & $.46^{* *}$ & $.36^{* *}$ & $-.44^{\star *}$ & -.12 & $-.37^{* *}$ \\
\hline 2. Loneliness & $.52^{\star *}$ & - & $.51 * *$ & $-.60^{* *}$ & $-.61^{* *}$ & $-.48^{* *}$ \\
\hline 3. Rejection sensitivity & $.40^{\star *}$ & $.45^{\star *}$ & - & $-.45^{\star *}$ & $-.32^{\star *}$ & $-.39^{* *}$ \\
\hline 4. Social competence & $-.35^{* *}$ & $-.66^{\star *}$ & $-.34^{\star *}$ & - & $.48^{\star *}$ & $.39^{* *}$ \\
\hline 5. Social support - friends & $-.23^{* *}$ & $-.58^{* *}$ & $-.27^{* *}$ & $.49^{* *}$ & - & $.48^{* *}$ \\
\hline 6. Social support - family & $-.34^{\star *}$ & $-.44^{* *}$ & $-.28^{* *}$ & $.42^{\star *}$ & $.45^{\star *}$ & - \\
\hline
\end{tabular}

${ }^{*} p<.05$, two-tailed ${ }^{* *} p<.01$, two-tailed.

Note: Correlations between Time 1 measures are presented below the diagonal. Correlations between Time 2 measures are presented above the diagonal. $N$ ranged from 109 to 130 .

\section{Distributions and Stability of Attachment Style}

Distributions and stability of attachment style were examined. As shown in Table 3, the size of each attachment style group was similar to the expected size, 
based on previous research (e.g., Brennan \& Morris, 1997). At T1, as expected from previous research, most participants $(66 \%)$ were classified as secure. The distribution of adolescents across the attachment classifications was similar at T2, with $63 \%$ of participants classified as secure.

\section{Table 3. Crosstabulation of Attachment Style Classifications at Time I (TI) and Time 2 (T2), and Stability of Attachment Over Time}

\begin{tabular}{|c|c|c|c|c|c|c|c|}
\hline & $\begin{array}{l}\text { T2 } \\
\text { Secure } \\
n=82\end{array}$ & $\begin{array}{l}\text { T2 } \\
\text { Insecure } \\
n=48\end{array}$ & $\begin{array}{l}\text { \% Un- } \\
\text { changed } \\
\text { T1 to T2 }\end{array}$ & $\begin{array}{l}\text { T2 } \\
\text { Fearful } \\
n=20\end{array}$ & $\begin{array}{l}\text { T2 Pre- } \\
\text { occupied } \\
n=15\end{array}$ & $\begin{array}{l}\text { T2 } \\
\text { Dismissing } \\
n=13\end{array}$ & $\begin{array}{l}\% \text { Un- } \\
\text { changed } \\
\text { T1 to T2 }\end{array}$ \\
\hline T1 Secure $n=86$ & 69 & 17 & $80 \%$ & 8 & 4 & 5 & - \\
\hline T1 Insecure $n=44$ & 13 & 31 & $70 \%$ & - & - & - & - \\
\hline T1 Fearful $n=22$ & 4 & - & - & 8 & 6 & 4 & $36 \%$ \\
\hline T1 Preoccupied $n=17$ & 6 & - & - & 4 & 5 & 2 & $29 \%$ \\
\hline T1 Dismissing $n=5$ & 3 & - & - & 0 & 0 & 2 & $40 \%$ \\
\hline
\end{tabular}

Note: For example, of the participants $(n=86)$ who were classified as secure at T1, 69 were secure at T2 and 17 were insecure at T2. Dividing 69 by 86 shows that $80 \%$ of participants who were secure at T1 also were secure at T2. Of the participants $(n=22)$ who were classified as fearful at T1, 6 were secure at T2, whereas 8 were fearful, 6 were preoccupied and 4 were dismissing. Dividing 8 by 22 shows that $36 \%$ of participants who were fearful at T1 also were fearful at $T 2$.

There was a significant association between $\mathrm{T} 1$ and $\mathrm{T} 2$ attachment classifications, $\chi^{2}(9, \mathrm{~N}=130)=44.07, p<.01$ (see Table 3). Overall, $64 \%$ of participants endorsed the same attachment style over time, and 36\% did not. When the four categories of attachment style were examined, the value of kappa was .34, representing a minimal to moderate rate of agreement and stability (Cicchetti \& Sparrow, 1981). When the dichotomous secure-insecure classification was examined, the value of kappa was .50 representing a moderate level of agreement (Cicchetti \& Sparrow). The secure attachment style showed the greatest stability over time, with $80 \%$ of participants who were classified as secure at T1 also classified as secure at $\mathrm{T} 2$.

Overall, $77 \%(n=100)$ of participants were stably secure or stably insecure, $\chi^{2}(1, N=130)=32.11, p<.01$. This meant that nearly one-quarter $(23 \%)$ of participants change attachment style from $\mathrm{T} 1$ to $\mathrm{T} 2$ by endorsing the secure attachment pattern at one assessment (either T1 or T2) and an insecure pattern at the other assessment. To investigate attachment stability further, correlations between $\mathrm{T} 1$ and $\mathrm{T} 2$ ratings on the four continuous attachment items were examined. Correlations were all positive and significant, although surprisingly moderate in magnitude, $r_{\text {SECURE }}=.41, p<.01, r_{\text {FEARFUL }}=.46, p<.01, r_{\text {PREOCCUPIED }}=.30, p<.01$, $r_{\text {Dismissing }}=.35, p<.01$. Together, these crosstabulations and correlations support the hypothesis that attachment style was minimally to moderately stable over the six months of this study. 


\section{Correlates of Attachment Style Change and Stability}

\section{Examination of analytical assumptions and overview of analyses}

As expected, some distributions of variables departed from normality and were positively skewed (e.g., psychological symptoms, loneliness). However, the violations of normality were relatively minor. Consequently, no corrective action was taken to adjust skew (i.e., data were not transformed), but nonparametric statistical analyses were conducted to confirm findings from parametric techniques (t-tests, analysis of variance) and the impact of outliers, leverage and influential points was continually assessed throughout each analysis. In some analyses, the assumption of homogeneity of variance was violated (Box's M test $p<.05$ but always $>.01$ ), most likely due to the small, uneven cell sizes. In these instances Pillai's Trace was interpreted, otherwise Wilks' lambda was used. When equality of variances could not be assumed, Dunnett's post hoc comparisons were performed. When equality of variances could be assumed, Bonferroni's post hoc comparisons were used.

\section{Parametric statistical methods}

Four groups were formed. These groups were (a) stably secure (individuals categorised as secure at T1 and T2), (b) stably insecure (individuals categorised as insecure at T1 and T2), (c) changed to secure (individuals categorised as insecure at T1 and secure at T2), and (d) changed to insecure (individuals categorised as secure at $\mathrm{T} 1$ and insecure at $\mathrm{T} 2$ ). These groups will be referred to as attachment change groups. To test the hypotheses regarding correlates of stability and change in attachment style, a series of 4 (attachment change groups) $\times 2$ (time) repeated measures analysis of variance (ANOVA) models were used, followed by post hoc comparisons. Analyses were then repeated after excluding respondents who provided inconsistent responses about attachment within a wave of assessment (approximately $10 \%$ of longitudinal sample), and individual outliers. Any changes to the primary results were noted.

\section{Nonparametric statistical methods}

Although ANOVA can be robust to violations of some statistical assumptions, the accuracy of the results is dependent on the degree to which the data meet the assumptions (e.g., normality and homogeneity of variance; Harwell \& Serlin, 1997). When violations of assumptions are observed and sample sizes are not large, alternatives to parametric tests are recommended. One alternative is to use nonparametric methods. The advantage of a nonparametric statistical method is that fewer assumptions are made about the patterns of data and Harwell (1988) has argued that when the assumption of normality is violated (e.g., skewed distributions) or heteroscedasticity exists, nonparametric procedures will maximise power, compared with the equivalent parametric test. Given some of the minor deviance from the assumption of homogeneity of variance, normality in the current data, and the sample size, nonparametric statistics techniques were performed as a complement to ANOVA. The nonparametric test used was the Kruskal-Wallis One-Way Analysis of Variance (Kruskal-Wallis test) by ranks. 
Before using the Kruskal-Wallis test, a 'change score' was created by subtracting T1 dependent variable scores from the parallel T2 scores (e.g., psychological symptoms), and these ranked scores were compared between groups (Siegel, 1956).

\section{Psychological Symptoms and Loneliness}

Of most importance here was the significant attachment change groups by time interactions for psychological symptoms, Pillai's trace $=.07, F(3,125)=3.20$, $p<.05$, and for loneliness, Wilks' Lambda $=.93, F(3,126)=2.95, p<.05$ (see Figure 1). Paired-sample $t$-tests confirmed that individuals who were stably secure and insecure had no change in psychological symptoms and loneliness over time, while those who changed to secure had decreasing symptoms, $t(11)$ $=3.72, p<.05$, and decreasing loneliness over time, $t(12)=3.35, p<.01$. Not as expected, however, adolescents who changed to insecure had stable psychological symptoms and loneliness.

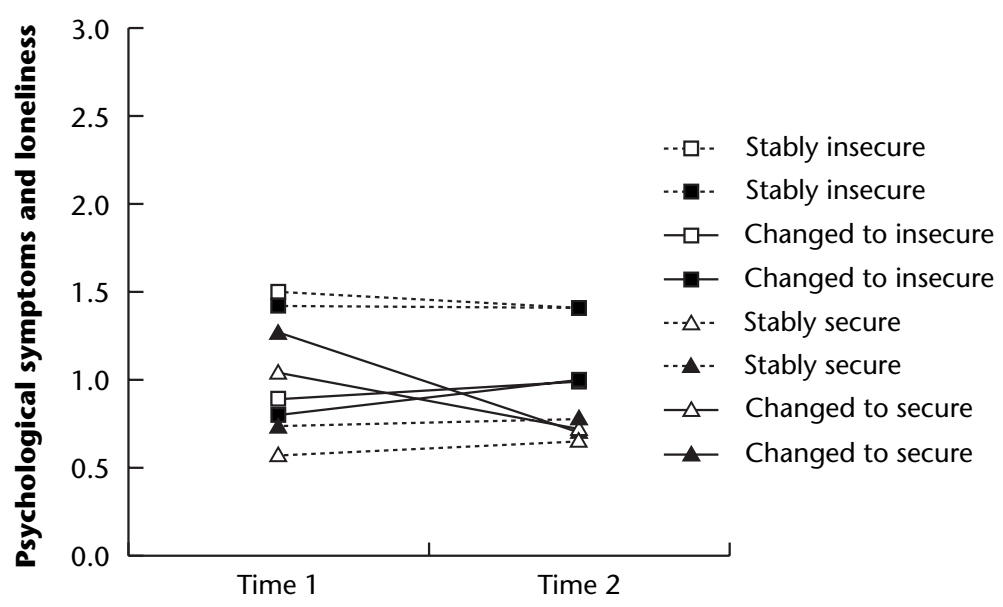

\section{Figure I. Mean TI and T2 psychological symptoms and loneliness by attachment change group.}

Note: Triangles indicate secure at Time 2. Squares indicate insecure at Time 2. Hatched lines indicate stable attachment groups. Solid lines indicate changing attachment groups. Filled markers indicate psychological symptoms. Open markers indicate loneliness.

Significant main effects for attachment change groups indicated that there were group differences in psychological symptoms, $F(3,125)=9.46, p<.01$, and loneliness, $F(3,126)=36.40, p<.01$. As expected, stably secure adolescents reported fewer symptoms, $M=.76$, than stably insecure, $M=1.42$, and changed 
to insecure participants, $M=.91, p<.05$. Additionally, stably insecure adolescents were more lonely, $M=1.46$, compared with the three other groups, changed to secure $M=0.86$, changed to insecure $M=0.94$, stably secure $M=0.61$, all $p<$ .05. No main effect for time was observed for psychological symptoms, Wilks' $F(1,126)=2.09$, or for loneliness, $F(1,125)=1.05$. The exclusion of respondents who had inconsistencies in reporting of attachment did not alter results in any meaningful way and results were supported by similar findings with nonparametric Kruskal-Wallis tests.

\section{Rejection Sensitivity}

There was a significant interaction between attachment change groups and time, Wilks' Lambda $=.94, F(3,126)=2.76, p<.05$ (see Figure 2). Paired-samples $t$-tests showed that stably insecure adolescents and those who changed to secure had no significant change in levels of rejection sensitivity over time. As expected, individuals in the changed to insecure group increased in rejection sensitivity, and unexpectedly, stably secure individuals decreased in rejection sensitivity over time.

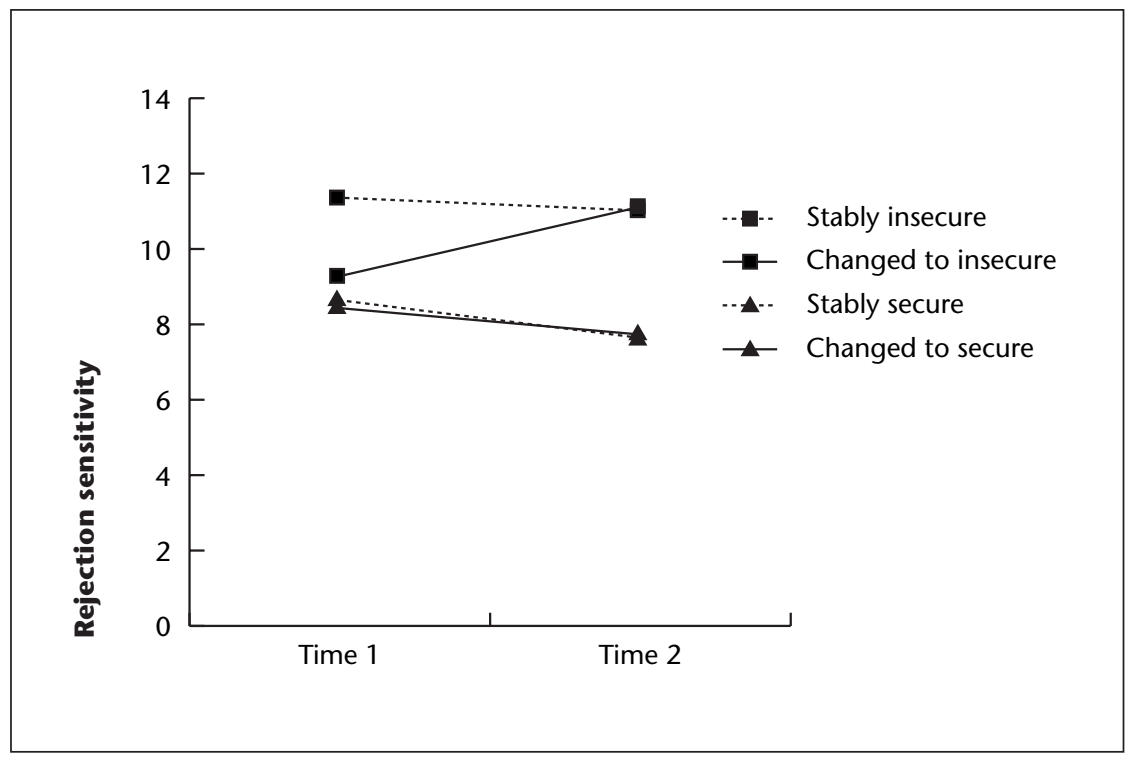

Figure 2. Mean TI and T2 rejection sensitivity by attachment change group.

Note: Triangles indicate secure at Time 2. Squares indicate insecure at Time 2. Hatched lines indicate stable attachment groups. Solid lines indicate changing attachment groups.

There also was a significant main effect for attachment change groups indicating group differences in rejection sensitivity, $F(3,126)=7.27, p<.01$. As predicted, stably insecure participants had higher rejection sensitivity, $M=$ 11.17, compared with stably secure, $M=8.14, p<.01$, and changed to secure 
adolescents, $M=8.09, p<.05$. There was no significant main effect of time, Wilks' $F(1,126)=0.03, p>.05$.

The exclusion of respondents who had inconsistent reports of attachment with a wave of measurement did not alter results. The nonparametric KruskalWallis test replicated findings with one discrepancy. Adolescents in the stably secure and stably insecure groups did not differ, indicating comparable (and little) change in rejection sensitivity over time.

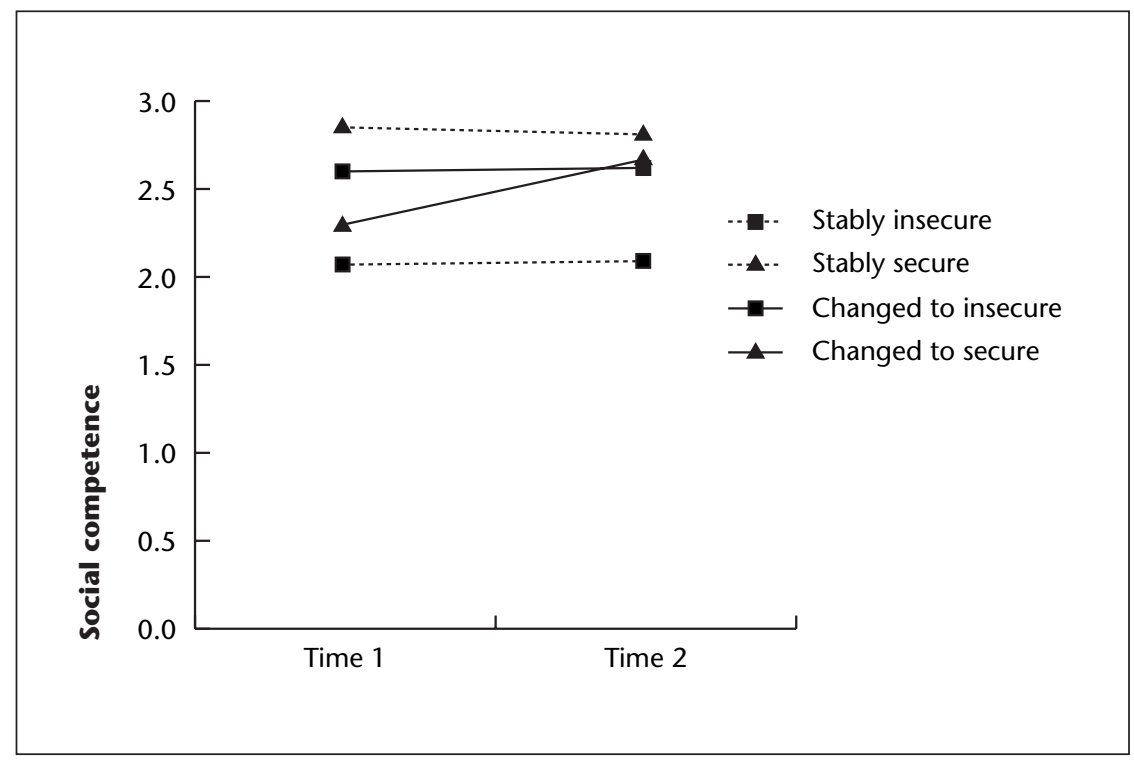

\section{Figure 3. Mean TI and T2 social competence by attachment change group.}

Note: Triangles indicate secure at Time 2. Squares indicate insecure at Time 2. Hatched lines indicate stable attachment groups. Solid lines indicate changing attachment groups.

\section{Social Competence and Social Support}

For all three dependent variables of social competence, social support from friends, and social support from family, repeated measures ANOVAs revealed no significant interactions between attachment change groups and time, social competence $F(3,124)=.67$, social support from friends $F(3,125)=1.96$, social support from family $F(3,124)=.09$. There also was no significant effects for time, social competence $F(1,125)=2.27$, social support from friends $F(1,124)$ $=.53$, social support from family $F(1,124)=2.34$, respectively. However, there was a significant main effect for attachment change groups on all measures, social competence $F(3,125)=11.73, p<.01$ (see Figure 3 ), social support from friends $F(3,124)=21.68, p<.01$ (see Figure 4), and from family $F(3,124)=13.92$, $p<.01$ (see Figure 4). Inspection of the means, in conjunction with Bonferroni's post hoc comparisons, showed that stably secure adolescents had more social competence, $M=2.74$, than stably insecure adolescents, $M=2.11$. As expected, 
stably insecure participants had less friend social support, $M=0.57$, compared with stably secure participants, $M=0.88, p<.05$, and those who changed to secure, $M=.83, p<.05$. Also as expected, stably secure participants had more family social support, $M=.84$, compared with stably insecure participants, $M=$ $.51, p<.01$, and adolescents who changed to insecure, $M=.65, p<.05$. Results were not altered when individuals were excluded who had provided inconsistent reports of attachment and all results were replicated with nonparametric Kruskal-Wallis tests.

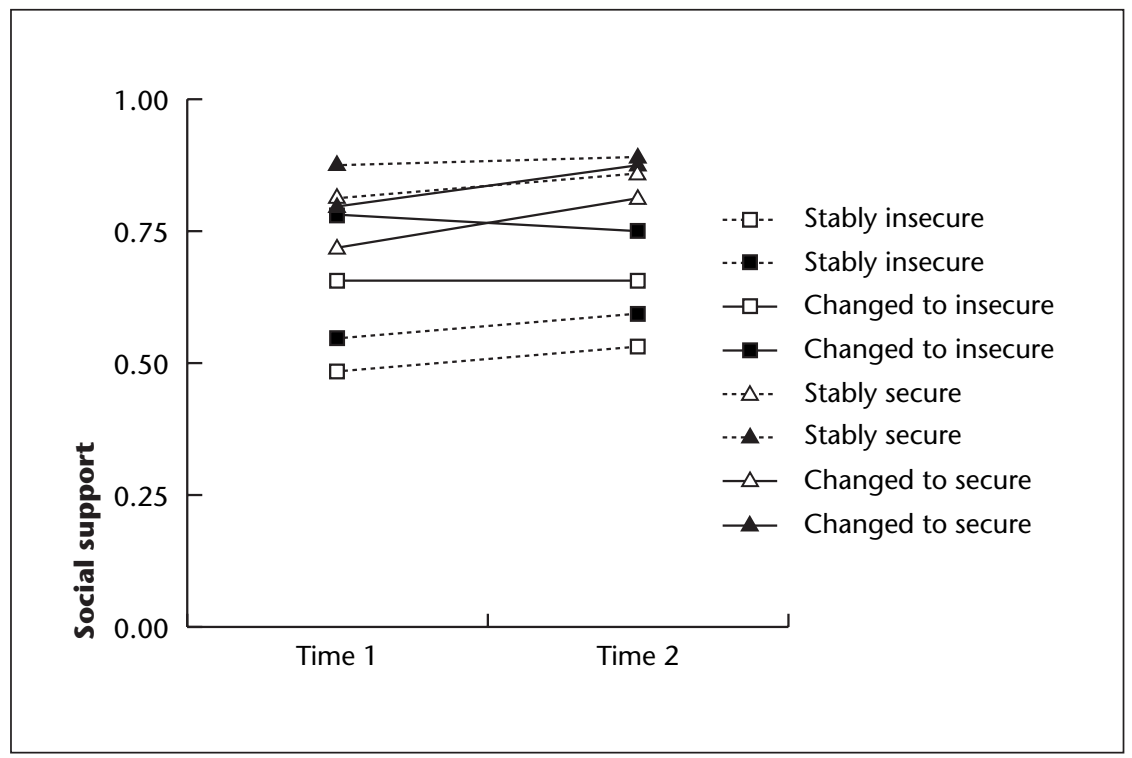

\section{Figure 4. Mean TI and T2 social support from friends and family by attachment change group.}

Note: Triangles indicate secure at Time 2. Squares indicate insecure at Time 2. Hatched lines indicate stable attachment groups. Solid lines indicate changing attachment groups. Filled markers indicate support from friends. Open markers indicate support from family.

\section{Discussion}

A basic premise of attachment theory is that internal working models are relatively stable, yet flexible and capable of change in response to new insights and relational experiences (Bowlby, 1977; Feeney \& Noller, 1996). As expected, self-reported attachment style was moderately stable in the current study. When four categories of secure, dismissing, fearful, and preoccupied attachment style were identified, approximately two-thirds of adolescents reported stable attachment style during Year 12. The other third endorsed different attachment styles across a 6-month period. The present findings support the theoretical expectation that attachment style will be moderately stable, yet is not always fixed and unchangeable. 
It was somewhat difficult to draw direct comparisons between the stability rates of attachment style found here and those reported in previous studies. First, the majority of previous research on attachment style has recruited older participants (usually university students). Second, Hazan and Shaver's (1987) three-category measure and the adult version of Bartholomew and Horowitz's Relationship Questionnaire have often been used, rather than a measure of attachment developed for adolescents as was used here. With these two issues in mind, the rate of stability of self-reported attachment style observed in the current study does appear compatible with other longitudinal studies with similar lags between assessments.

A second aim of the current study was to examine correlates of attachment style stability and change over time. Two stable attachment style groups were identified and labelled stably secure and stably insecure. Two additional groups had changing attachment style; they were categorised as insecure at T1 and secure at T2, or vice versa. These groups were labelled changed to secure and changed to insecure, respectively. Overall, findings accord well with theoretical expectations (Bowlby, 1977), and the numerous cross-sectional (see Greenberg, 1999) and few longitudinal studies (Cozzarelli et al., 2003; Davila et al., 1997) that have indicated that secure individuals are better adjusted and less vulnerable to experiencing psychological problems. In particular, when the four attachment stability/change groups were compared, a key finding was that, as predicted, stably secure individuals had discernibly more positive psychological functioning and stable perceptions of self and others when compared to the other three groups. Adolescents in the stably secure group reported fewer psychological symptoms compared with stably insecure individuals. Additionally, adolescents who maintained a secure attachment style were less lonely, perceived greater social support from friends and family, and were less sensitive to rejection, than their stably insecure peers.

There was partial support for the hypothesis that changes in dichotomous attachment style (i.e., changed to secure and changed to insecure) would be associated with corresponding changes in psychological symptoms and perceptions of self and others. As predicted, when secure attachment emerged, improvements in functioning, including decreasing psychological symptoms, loneliness and rejection sensitivity, were found. The opposite pattern was not as clear in the changed to insecure group. However, both of these groups were relatively small in size, and there was some indication that the changed to insecure group was experiencing some increases in loneliness and psychological symptoms, with the expected pattern emerging, but not reaching significance.

Some unexpected results must be highlighted. As hypothesised, adolescents who changed from a secure to an insecure attachment style were increasingly sensitive to rejection. Yet, adolescents who had the opposite pattern, changing from insecure to secure, did not show the expected decrease in rejection sensitivity over time, but stably secure adolescents did reported less sensitivity to rejection over time. Mikulincer and Florian (2001) have argued that a secure attachment style serves as a resilience factor, due to an optimistic attitude towards life, basic 
trust of the world, and the tendency to acknowledge distress and seek support when needed. This argument, coupled with our findings, suggests that a secure attachment style in adolescence that remains stable over time seems to come with increasing adaptation that is marked by declining anxiety about rejection and lowered expectations of rejection by others.

Finally, there was no support for the hypothesised correlations between attachment style change and changes in social competence and social support over time. There are at least three potential explanations for these findings. First, it is feasible that the 6-month period was not long enough for individuals to experience changes in their perceptions of social competence and social support from family/friends. An additional assessment another six months or one year later might clarify this issue, as well as providing more confidence in patterns of change and stability. Second, the measures of social competence and social support may have not been sensitive enough to detect short-term changes. On the perceived social support for friends and family measures, there was only provision for 'yes' or 'no' responses. A measure that could detect more subtle changes would be preferable in future research. Third, the changes observed in general attachment style might actually be changes in specific attachment relationships. Collins and Read (1994) argued that individuals have multiple attachment orientations that are organised in a hierarchical network. At the peak of the hierarchy is general attachment style (assessed in the current study), with more specific working models for particular types of relationships occupying lower levels of the hierarchy (e.g., parents, peers, partners). Although participants in the current study were instructed to think about their interactions with people 'in general', attachment style changes observed might reflect changes in more specific attachment relationships, which may not be associated with social competence and social support. To directly address this issue, future studies should employ methods to activate the part of the attachment hierarchy under investigation (e.g., parents or peers; Collins \& Read).

\section{Limitations, Future Research Directions and Conclusions}

It is important to acknowledge that some of the instability in attachment style may reflect measurement error. Some researchers have interpreted change in attachment style over time as "real" and meaningful change (Baldwin \& Fehr, 1995), yet others argue it is due to an unreliable instrument (e.g., Scharfe \& Bartholomew, 1994). As recommended by Mikulincer (Mikulincer, Florian, \& Tolmacz, 1990), both a categorical and a continuous measure of attachment were used in the current study to detect inconsistent responses. Interestingly, the degree of inconsistency between these different measures at a single time was only marginally higher when compared to the degree of instability across 6 months. It seems that, regardless of the time lag and whether different measures at one time or repeated measures across time are used, the rate of inconsistency (i.e., change in the case of repeated measures) is similar. Nevertheless, in the current study, the use of a single-item categorical measure was justified so that a clear indication of change would emerge and results rarely 
changed after excluding adolescents with inconsistent responses within a wave of measurement. However, this issue that some observed changes may be due to measurement error must be considered when interpreting the findings.

While it is important that future research replicate these results using other measures of attachment, the current study findings are strengthened by a number of observations. First, the stability data (e.g., kappa, test-retest correlations) are consistent with other studies that have used the adult version of the same measure (e.g., Cozzarelli et al., 2003; Scharfe \& Bartholomew, 1994) and multi-item measures (e.g., Collins \& Read, 1990). Second, because change in attachment style was demonstrated to be associated with changes in other key variables (e.g., psychological symptoms), this bolsters the argument that changes observed in attachment style were meaningful and not simply random measurement error (see also Baldwin \& Fehr, 1995 for this argument). A fair conclusion would be that the observed instability can be attributed to both 'true' change and measurement error.

The current study was also limited by the use of only two times of assessment and self-report measures. The use of only two waves of data collection makes it is unclear whether the changes in attachment and other constructs represent enduring and stable shifts in attachment patterns, or temporary fluctuations. The use of self-report measures makes all assessments susceptible to social desirability and other biases. Some research has demonstrated that self-report differs from interview-assessed attachment style (Shaver \& Mikulincer, 2006). It is recommended that future research incorporates multiple measures of attachment, such as interview-based measures of attachment (George, Kaplan, \& Main, 1985), and buttress these reports with observational data from friends, parents or teachers. Yet, the validity of adolescent attachment interviews has been questioned, as some researchers have found that adolescents (compared with adults) are more reserved and reticent when participating in interviews (see Allen \& Land, 1999). In contrast, the value of self-report measures has been demonstrated in much previous research (Shaver \& Mikulincer).

In summary, a stably secure attachment style during the last year of high school is associated with the best profile of functioning, and the emergence of a secure attachment style also is associated with improvements in functioning on measures of psychological well-being, loneliness and rejection sensitivity. Adolescents classified as stably insecure seem to have elevated challenges and problems, but adolescents who changed from secure to insecure attachment did not show decreases in functioning. The current findings predominantly support the theoretical proposition that attachment styles are associated with expectations, beliefs and perceptions about the self, others, and the broader social world. Middle adolescence, from a normative perspective, is an important developmental period, where the social world may radically expand. More examinations of attachment during this time of life will add to the growing body of literature regarding attachment processes as young people form their own intimate, close relationships and, hopefully, find additional sources of security outside the family (Collins \& Sroufe, 1999). Studies such as this one fill the gap between 
studies of attachment in childhood and studies conducted with university students and adults.

\section{Address for correspondence}

Melanie J. Zimmer-Gembeck

School of Psychology (GPY)

Griffith University - Gold Coast Campus

PMB 50 GCMC

QLD

9726

Email: m.zimmer-gembeck@griffith.edu.au

\section{Acknowledgements}

A portion of this work was part of the postgraduate thesis of Jillian Petherick. We are extremely grateful to the students, principals and teachers who participated during a stressful and busy school year. We also extend a special thanks to Tammie Wilkinson for assistance with data collection.

\section{References}

Allen, J. P., \& Land, D. (1999). Attachment in adolescence. In J. Cassidy \& P. R. Shaver (Eds.), Handbook of attachment: Theory, research, and clinical applications (pp. 319-335). New York: The Guilford Press.

Anders, S. L., \& Tucker, J. S. (2000). Adult attachment style, interpersonal communication competence, and social support. Personal Relationships, 7, 379-389.

Ayduk, O., Mendoza-Denton, R., Mischel, W., Downey, G., Peake, P. K., \& Rodriguez, M. (2000). Regulating the interpersonal self: Strategic selfregulation for coping with rejection sensitivity. Journal of Personality and Social Psychology, 79, 776-792.

Baldwin, M.W., \& Fehr, B. (1995). On the stability of attachment style ratings. Personal Relationships, 2, 247-264.

Bartholomew, K. (1994). Assessment of individual differences in adult attachment. Psychological Inquiry, 5, 23-67.

Bartholomew, K., \& Horowitz, L. M. (1991). Attachment styles among young adults: A test of a four category model. Journal of Personality and Social Psychology, 61, 226-244.

Bowlby, J. (1973). Attachment and loss: Vol. 2. Separation: Anxiety and anger. New York: Basic Books.

Bowlby, J. (1977). The making and breaking of affectional bonds. British Journal of Psychiatry, 130, 201-210.

Brennan, K. A., \& Morris, K. A. (1997). Attachment styles, self-esteem, and patterns of seeking feedback from romantic partners. Personality and Social Psychology Bulletin, 23, 23-32.

Cicchetti, D. V., \& Sparrow, S. A. (1981). Developing criteria for establishing inter-rater reliability of specific items: Applications to assessment of adaptive behaviour. American Journal of Mental Deficiency, 86, 127-137. 
Collins, N. L., \& Allard, L. M. (2001). Cognitive representations of attachment: The content and function of working models. In G. J. O. Fletcher \& M. S. Clark (Eds.), Blackwell handbook of social psychology: Interpersonal processes (pp. 60-85). Malden, MA: Blackwell Publishers.

Collins, N. L., \& Feeney, B. C. (2004). Working models of attachment shape perceptions of social support: Evidence from experimental and observational studies. Journal of Personality and Social Psychology, 87, 363-383.

Collins, N. L., \& Read, S. J. (1990). Adult attachment, working models, and relationship quality in dating couples. Journal of Personality and Social Psychology, 58, 644-663.

Collins, N. L., \& Read, S. J. (1994). Cognitive representations of attachment: The structure and function of working models. Advances in Personal Relationships, 5, 53-90.

Collins, W. A., \& Sroufe, A. (1999). Capacity for intimate relationships: A developmental construction. In W. Furman, B. B. Brown, \& C. Feiring (Eds.), Development of romantic relationships in adolescence (pp. 125-147). New York: Cambridge University Press.

Cozzarelli, C., Karafa, J. A., Collins, N. L., \& Tagler, M. J. (2003). Stability and change in adult attachment styles: Associations with personal vulnerabilities, life events, and global construals of self and others. Journal of Social and Clinical Psychology, 22, 315-346.

Davila, J., Burge, D., \& Hammen, C. (1997). Why does attachment style change? Journal of Personality and Social Psychology, 73, 826-838.

Davis, M. H., Morris, M. M., \& Kraus, L. (1998). Relationship-specific and global perceptions of social support: Associations with well-being and attachment. Journal of Personality and Social Psychology, 74, 468-481.

Derogatis, L. R., \& Melisaratos, N. (1983). The Brief Symptom Inventory: An introductory report. Psychological Medicine, 13, 595-605.

Downey, G., \& Feldman, S. I. (1996). Implications of rejection sensitivity for intimate relationships. Journal of Personality and Social Psychology, 70, 13271343.

Egeland, B., \& Farber, E. (1984). Infant-mother attachment: Factors related to its development and changes over time. Child Development, 55, 753-771.

Feeney, J., \& Noller, P. (1996). Adult attachment. London: Sage Publications.

Feldman, S., \& Downey, G. (1994). Rejection sensitivity as a mediator of the impact of childhood exposure to family violence on adult attachment behaviour. Development and Psychopathology, 6, 231-247.

George, C., Kaplan, N., \& Main, M. (1985). The Attachment Interview for Adults. Unpublished manuscript, University of California, Berkeley.

Greenberg, M. T. (1999). Attachment and psychopathology in childhood. In J. Cassidy \& P. R. Shaver (Eds.), Handbook of attachment: Theory research, and clinical applications (pp. 469-496). New York: The Guilford Press.

Griffin, D. W., \& Bartholomew, K. (1994). The metaphysics of measurement: The case of adult attachment. Advances in Personal Relationships, 5, 17-52.

Harwell, M. R. (1988). Choosing between parametric and nonparametric tests. Journal of Counseling and Development, 67, 35-38. 
Harwell, M. R., \& Serlin, R. C. (1997). An empirical study of five multivariate tests for the single-factor repeated measures model. Community Statistician - Simulation, 26, 605-618.

Hazan, C., \& Shaver, P. R. (1987). Romantic love conceptualized as an attachment process. Journal of Personality and Social Psychology, 52, 511-524.

Helmreich, R., \& Stapp, J. (1974). Short forms of the Texas Social Behaviour Inventory (TSBI), objective measure of self-esteem. Bulletin of the Psychonomic Society, 4, 473-475.

Kirkpatrick, L. A., \& Hazan, C. (1994). Attachment styles and close relationship: A four-year prospective study. Personal Relationships, 1, 123-142.

Kobak, R. R., \& Sceery, A. (1988). Attachment in late adolescence: Working models, affect regulation, and representations of self and others. Child Development, 59, 135-146.

Larose, S., \& Boivin, M. (1997). Structural relations among attachment working models of parents, general and specific support expectations, and personal adjustment in late adolescence. Journal of Social and Personal Relationships, 90, 1015-1030.

Lewis, M., Feiring, C., \& Rosenthal, S. (2000). Attachment over time. Child Development, 71, 707-720.

Lopez, F. G., \& Gormley, B. (2002). Stability and change in adult attachment style over the first-year college transition: Relations to self-confidence, coping, and distress patterns. Journal of Counseling Psychology, 49, 355-364.

Mikulincer, M., \& Florian, V. (2001). Attachment style and affect regulation Implications for coping with stress and mental health. In G. J. O. Fletcher \& M. S. Clark (Eds.), Blackwell handbook of social psychology: Interpersonal processes (pp. 537-557). Malden, MA: Blackwell Publishers.

Mikulincer, M., Florian, V., \& Tolmacz, R. (1990). Attachment styles and fear of personal death: A case study of affect regulation. Journal of Personality and Social Psychology, 58, 273-280.

Ognibene, T. C., \& Collins, N. L. (1998). Adult attachment styles, perceived social support and coping strategies. Journal of Social and Personal Relationships, 15, 323-345.

Pistole, M. C. (1989). Attachment in adult romantic relationships: Style of conflict resolution and relationship satisfaction. Journal of Social and Personal Relationships, 6, 505-510.

Procidano, M. E., \& Heller, K. (1983). Measures of perceived social support from friends and from family: Three validation studies. American Journal of Community Psychology, 11, 1-24.

Russell, D., Peplau, L. A., \& Cutrona, C. E. (1980). The Revised UCLA Loneliness scale: Concurrent and discriminant validity evidence. Journal of Personality and Social Psychology, 39, 472-480.

Scharfe, E. (not dated). The Adolescent Relationship Questionnaire. Retrieved January 2004, from Trent University, Psychology Web site: http://www. trentu.ca/psychology / escharfe/RQ.HTM.

Scharfe, E., \& Bartholomew, K. (1994). Reliability and stability of adult attachment patterns. Personal Relationships, 1, 23-43. 
Searle, B., \& Meara, N. M. (1999). Affective dimensions of attachment styles: Exploring self-reported attachment style, gender, and emotional experience among college students. Journal of Counseling Psychology, 46, 147-158.

Shaver, P. R., \& Clark, C. L. (1994). The psychodynamics of adult romantic attachment. In J. M. Masling \& R. F. Bornstein (Eds.), Empirical perspectives on object relations theory (pp. 105-156). Washington, DC: American Psychological Association.

Shaver, P. R., \& Mikulincer, M. (2006). What do self-report attachment measures assess? In W. S. Rholes \& J. A. Simpson (Eds.), Adult attachment: Theory, research, and clinical implications (pp. 17-54). New York: Guilford.

Siddique, C. M., \& D'Arcy, C. (1984). Adolescence, stress, and psychological well-being. Journal of Youth and Adolescence, 13, 459-473.

Siegel, S. (1956). Nonparametric statistics for the behavioural sciences. London: McGraw-Hill Kogakusha.

Simpson, J. A., Rholes, W. S., Campbell, L., \& Wilson, C. L. (2003). Changes in attachment orientations across the transition to parenthood. Journal of Experimental Social Psychology, 39, 317-331.

Waters, E., Weinfield, N. S., \& Hamilton, C. E. (2000). The stability of attachment security from infancy to adolescence and early adulthood: General discussion. Child Development, 71, 703-703. 